\title{
USO/COBERTURA DE LA TIERRA EN LOS CANTONES DE UPALA, GUATUSO Y LOS CHILES EN EL AÑO 2011
}

\author{
LAND COVER/USE IN THE CANTONS OF UPALA, \\ GUATUSO AND LOS CHILES IN THE YEAR 2011
}

\author{
Omar Barrantes Sotelal \\ Luis Sandoval Murillo \\ Universidad Nacional de Costa Rica
}

\section{RESUMEN}

El Uso de la tierra es una herramienta fundamental para identificar las diversas actividades agroeconómicas y los recursos naturales, presentes en un área determinada. Sin embargo, la evidente desactualización en más de treinta y cinco años de la información espacial sobre los usos y coberturas de la tierra en los cantones Upala, Guatuso y Los Chiles de la provincia Alajuela, Costa Rica limita la toma de decisiones entorno al ordenamiento territorial; el cual busca sustentar un desarrollo equilibrado entre los diversos actores presentes en el territorio.

Mediante el uso de métodos de teledetección se identifican los principales usos y coberturas de la tierra en el año 2011 en estos cantones, información que es utilizada como un instrumento decisivo en la generación de otros insumos necesarios en la elaboración de las propuestas técnicas sobre la planificación y el ordenamiento territorial de la zona.

1 Académico Escuela de Ciencias Geográficas de la Universidad Nacional de Costa Rica. Correo electrónico: obarrantes@gmail.com

2 Académico Escuela de Ciencias Geográficas de la Universidad Nacional de Costa Rica. Correo electrónico: luifersandoval@gmail.com 
Omar Barrantes Sotela, Luis Sandoval Murillo. Uso/cobertura de la tierra en los cantones de Upala, Guatuso y Los Chiles en el año 2011

DOI: http://dx.doi.org/10.15359/rgac.1-56.3

Palabras clave: Uso de la tierra, coberturas de la tierra, planificación territorial, ordenamiento territorial, SIG, sensores remotos, plan regulador, Zona Norte-Norte.

\begin{abstract}
The use of land is essential to identify different agro-economic activities and natural resources present in a specific area. However, the lack of updated spatial information-for more than thirty-five years, regarding the uses and coverages of land in Upala, Guatuso and Los Chiles, Alajuela, Costa Rica has limited the decision-making process concerning land planning, which aims at supporting a balanced development between different entities in the territory.

Using remote sensing methods major land uses and land covers were identified in 2011 for these cantons. This information serves as a critical tool to generate other inputs required in the preparation of technical proposals on planning and land use planning.
\end{abstract}

Keywords: Land use, land coverage, territorial planning, land-use planning, urban master plan, GIS, remote sensing, North-North Zone.

\title{
Introducción
}

La identificación de coberturas-uso del suelo y de los procesos de transformación del paisaje es un objetivo que comparten diversos temas de investigación, entre los cuales destacan la valoración y evaluación del impacto ecológico y antropológico; así como la determinación de los recursos (Bahadur, 2009; Huth et al., 2012; Muchoney et al., 2000; No-Wook, 2010). El estudio en la distribución de los usos del suelo y la tierra, se origina en muchas oportunidades de los patrones irregulares del aprovechamiento y la utilización de los recursos debido a las necesidades de la población. Según Mather (1986), Meyer \& Turner (1994), es frecuente la utilización inadecuada entre los conceptos cobertura de la tierra y uso de la tierra. El término cobertura de la tierra se refiere a solo la descripción física de la capa superficial de la tierra, lo que incluye vegetación, áreas sin vegetación y zonas humanas, mientras que el término uso de la tierra es la caracterización por actividades antropogénicas que modifican, manejan, conservan y usan los tipos o estados de coberturas de la tierra (Ramírez, 2001; Richters, 1995).

En diferentes investigaciones el enfoque utilizado para analizar el tema es la conservación de los recursos, la gestión del territorio, la planificación y el ordenamiento territorial (Alarcón, 2006), donde se procura un desarrollo sostenible tanto del medio ambiente como el mejoramiento social de la población y que pueden convertirse en recomendaciones para la gestión de recursos, fundamentadas en acciones de planificación, 
regulaciones y ordenanzas a nivel local y regional (Smith \& Giraud, 2006; Wilhelm-Rechmann \& Cowling, 2013).

A pesar de la importancia señalada de disponer de información cartográfica actualizada del uso de la tierra, muchos sectores o regiones de Costa Rica carecen de este tipo de insumo, lo que dificulta la ejecución de un proceso de planificación territorial, que garantice el diseño de propuestas concretas para fomentar un desarrollo balanceado entre los diferentes actores del territorio. Un claro ejemplo de lo anterior se evidencia en la Zona Norte de Costa Rica, la cual presenta un proceso de degradación ambiental generado por el desarrollo de ciertas actividades productivas agropecuarias, cambios en el uso del suelo, la deforestación, el dragado de humedales y los incendios forestales; que a su vez provocan presión en las coberturas naturales o ecosistemas frágiles (IICA, MAG-PDR, UCR, 2007).

La evaluación de los usos de la tierra tiene un fuerte arraigo y orientación en las Ciencias Geográficas, ya que es a través del mapeo y la descripción de procesos espaciales, relacionando la extensión, la distribución, la estructura y la evolución del uso de la tierra o del mosaico paisajístico en el tiempo (Huising, 1993; Tang, Wang \& Myint, 2007). Constituyendo procesos necesarios para analizar y explicar su construcción socio-económica, fundamentando este tipo de información como vital para predecir futuros cambios en los patrones de paisajes naturales y antrópicos, que a su vez son fuertes indicadores para guiar procesos de planificación agrícola y urbana, pero con un sentido orientado a satisfacer la sustentabilidad ambiental y económica en el territorio.

La utilización de imágenes satelitales y procesos de teledetección, son materiales y herramientas ampliamente aceptadas para la generación de información cartográfica relacionada a la cobertura/uso de la tierra (Ahmadi, Karamouz, Moridi, \& Han, 2012; Bahadur, 2009; Baraldi, Bruzzone, \& Blonda, 2005; Huising, 1993; Huth et al., 2012; Leo, Eijsackers, Koelmans, \& Vijver, 2008; Muchoney et al., 2000; No-Wook, 2010; Smith \& Giraud, 2006). A su vez, se debe recordar que la resolución espacial y espectral de las imágenes es un parámetro que define la escala del mapa resultante (Marçal, Borges, Gomes, \& Da Costa, 2005). Para efectos de la planificación en Costa Rica, el decreto ejecutivo 32967 en su artículo 5.14.2 indica que estudios en planificación local o para propuestas técnicas de Planes Reguladores, la escala de trabajo debería estar en un rango de 1:5 000 y 1:50 000, 
Omar Barrantes Sotela, Luis Sandoval Murillo. Uso/cobertura de la tierra en los cantones de Upala, Guatuso y Los Chiles en el año 2011

DOI: http://dx.doi.org/10.15359/rgac.1-56.3

es decir, un tamaño de píxel de $2 \mathrm{~m}$ a $15 \mathrm{~m}$, lo que aseguraría una adecuada representación cartográfica de usos/coberturas de la tierra.

Del mismo modo, el procesamiento o interpretación de la información satelital se realiza por medio de complejos algoritmos o clasificadores. Estos clasificadores requieren la identificación de ciertos elementos o patrones en las imágenes como tono, color, tamaño y forma; articulándolos bajo un criterio de conocimiento de los objetos que se buscan identificar, es decir debe existir un conocimiento a priori del objeto o clase. En la elaboración de información de las coberturas de uso de la tierra existe un problema común, el cual es la selección de las propiedades determinantes o relevantes del objeto.

Uno de las características más utilizadas en los procesos de identificación de usos, es el análisis de los píxeles en la imagen, específicamente concentrándose en la propiedad física de los cuerpos de reflejar, absorber y transmitir radiación, la cual puede variar considerablemente según la época del año, hora de la captura de la imagen y las propiedades intrínsecas del objeto. La radiación que es reflejada por un objeto se le denomina radiancia, y es la información que captura un sensor remoto. Estos sensores reciben la radiación reflejada por un objeto en la dirección dentro del ángulo de vista del instrumento. Los sensores dentro del aparato son sensibles a tal radiancia y producen un voltaje que es medido, y por medio de una calibración se relaciona a la radiancia, es decir, los clasificadores usan la medición de la radiancia de la imagen como propiedad física del objeto (respuesta del patrón espectral de onda electromagnética) y que, posteriormente, puede ser asociada con una medición en el terreno del objeto.

Huising (1993), señala en una experiencia anterior de clasificación de imágenes satelitales en la zona del Caribe de Costa Rica, que si bien al usar procesos y técnicas basadas en sensores remotos, se facilita la realización de inventarios de coberturas de uso, en el caso de Costa Rica esta identificación de usos de la tierra puede estar limitada. Principalmente, a la dificultad de establecer una distinción entre algunas clases o categorías, produciendo el efecto denominado "clasificación de conjuntos difusos". Esto ocurre ya sea por las características de un patrón espectral difuso similar o por la semejanza de tonos y formas entre los objetos. Esto complica el proceso de inferencia del conjunto de datos asociados a las escenas fotogramétricas, debido a las características de la vegetación y la topografía 
presentes en el país. También Baraldi et al. (2005), Huising (1993), indican que el uso de ciertos clasificadores para la interpretación de material fotogramétrico puede ser una actividad no estructurada y subjetiva; dando como consecuencia resultados de alguna manera con propagación de error y subjetividad asociada.

En la mayoría de los casos, los algoritmos de clasificación de imágenes están calibrados para otros contextos geográficos, con condiciones de áreas con una alta ocurrencia de los tipos de uso de la tierra y que además presentan una extensión superficial considerable, así como una forma o patrón reconocible. Bajo las anteriores características, los clasificadores reconocen y asignan valores en la matriz de datos de forma más eficiente, garantizando resultados con una calidad aceptable en términos cuantitativos. Esto facilita procesos de elaboración de Valoraciones Ecológicas Rápidas que utilizan variables como parámetros de vegetación, parámetros de hojas, propiedades ópticas y parámetros de físicos, así como de paisaje, hidrología y suelo (Muchoney et al., 2000). Sin embargo, en Costa Rica, la aplicación de las metodologías descritas en artículos científicos, informes técnicos u otras iniciativas gubernamentales con una escala de trabajo nacional o regional, solo han logrado generar mapas con una escala general y que temáticamente solo responden a un ejercicio práctico, más no funcional.

De manera estandarizada, un proceso de clasificación en cadena de sensores remotos conlleva las siguientes etapas: Pre-procesamiento de la información digital de la imagen, segmentación de la imagen, procedimiento de muestreo, chequeo de separabilidad de datos, separación de muestras o sitios de control (información de entrenamiento del sensor e información para validación del clasificador), creación del clasificador o combinación de algoritmos de clasificación, obtención de datos validados clasificados, validación general del proceso de interpretación de la imagen, matriz de confusión o de contingencia resultante y, finalmente, el indicador de concordancia. Del indicador de concordancia se realiza la valoración del proceso, si este no es aceptable el proceso debe revisarse (Huth et al., 2012).

Debido a las dificultades expuestas según Arroyo (2009) y Huising (1993), una de las limitaciones en la elaboración de coberturas de uso de la tierra en Costa Rica, es la obtención de información uniforme de 
Omar Barrantes Sotela, Luis Sandoval Murillo. Uso/cobertura de la tierra en los cantones de Upala, Guatuso y Los Chiles en el año 2011

DOI: http://dx.doi.org/10.15359/rgac.1-56.3

puntos de control en el terreno, principalmente por el costo asociado que conlleva el traslado de personal y equipo. Situación que generalmente limitó la exactitud de la valoración de los resultados en otras iniciativas de identificación de usos de la tierra en Costa Rica. Si además, se considera que el uso de la tierra al ser dinámico y evolucionar de manera heterogénea tanto espacial como temporal, requiere de una continua actualización y de monitoreo sistemático bajo criterios muy bien establecidos. Aún más en zonas como la región norte de Costa Rica, que debido a su modelo de crecimiento económico orientado hacia afuera, con un patrón territorial históricamente joven y orientado a la producción agropecuaria, es muy variable en términos estacionales de los cultivos (Barrantes \& Sandoval, 2013; ECG-UNA, 2012a, 2012b, 2012c), e implementar acciones relativas al monitoreo y evaluación de usos de la tierra, son actividades que deben considerarse como fundamentales o prioritarias.

El crear estructuras y modelos de datos a ser utilizadas mediante los Sistemas de Información Geográfica (SIG), agilizaría la adquisición, y el procesamiento de información, a una etapa de aplicación práctica para la toma de decisiones. Es decir, en contraste a la identificación de sistemas agrícolas que solo se orienta en los usos presentes como un censo agrícola. La evaluación de los usos de la tierra se enfoca en los usos potenciales y futuros de la tierra. Además, nuevas innovaciones en herramientas de manejo y planificación como los Sistemas de Soporte de Decisión (DDS) requieren de coberturas de usos de la tierra de alta calidad en sus bases de datos, y derivados de fotogrametría de alta resolución, tanto a una escala regional como local, y que preferiblemente este a una escala igual o inferior a 1:25 000, para satisfacer las necesidades de los tomadores de decisiones (Huth et al., 2012).

\section{Metodología}

El área de estudio abarca los cantones Upala, Guatuso y Los Chiles de la provincia de Alajuela, Costa Rica. Por su gran extensión $(3676,57$ km²) (Ver figura 1), contiene una gran diversidad de características en los ámbitos ambientales, económicos, sociales y culturales; y juega un papel importante dentro de la dinámica agrícola productiva de Costa Rica. Es una zona de altos contrastes, que posee una alta riqueza ambiental, pero también es una de las zonas más deprimidas en términos de desarrollo humano del país. Así lo refleja el índice de desarrollo humano (IDH), que para el año 2011, estos 
cantones ocupan las últimas posiciones del indicador de los 81 cantones de Costa Rica: Los Chiles (74), Guatuso (76) y Upala (59) (PNUD, 2013).

En la elaboración de cobertura de usos de la tierra, se utilizaron imágenes del sensor RapidEye, con resolución espacial de 5 metros y de 5 bandas espectrales del año 2010. Se aplicó un pre-procesamiento inicial a las imágenes, que consistió en una corrección radiométrica mediante la aplicación las ecuaciones de radiancia y reflectancia al número digital de las imágenes satelitales (Chuvieco, 1999; Riaño, Salas \& Chuvieco, 2000) y cuyos datos se obtienen en los metadatos de la escena y de las especificaciones del sensor (Ag, 2010; Krystyna \& Da, 2009; Naughton et al., 2011; Sampath \& Chander, 2010; Sampath, Haque, Chander \& Edge, 2011; Tapsall, Milenov \& Tas, 2010).

Radiancia:

$L_{\lambda}=$ Ganancia $*$ Valor de Pixel + Valor de compensación

$L_{\lambda}=\frac{Q_{c a l}}{100}$

Reflectancia:

$\rho_{\lambda}=\frac{\pi L_{\lambda} d^{2}}{E S U N_{\lambda} \sin \theta}$

Donde:

$L_{\lambda}=$ Radiancia en unidades de $\mathrm{W} /\left(\mathrm{m}^{2} * \mathrm{sr} * \mu \mathrm{m}\right)$

$d=$ Distancia Sol-Tierra, en unidades astronómicas.

$E S U N_{\lambda}=$ Irradiancia solar en unidades de $\mathrm{W} /\left(\mathrm{m}^{2} * \mu \mathrm{m}\right)$

$\theta=$ Elevación del Sol en grados decimales.

Con el propósito de normalizar y generalizar la firma espectral de las imágenes satelitales se utiliza un filtro estadístico por moda (majority resampling technique) a [4 x (5x5)] (20 m / pixel). Esta técnica facilita el proceso de clasificación supervisada, al reducir la dispersión radiométrica de las imágenes, por medio de la agrupación direccional de los valores de los pixeles. 
Omar Barrantes Sotela, Luis Sandoval Murillo. Uso/cobertura de la tierra en los cantones de Upala, Guatuso y Los Chiles en el año 2011

DOI: http://dx.doi.org/10.15359/rgac.1-56.3

El proceso de Clasificación Supervisada escogido es el método de máxima similitud, el cual genera para cada firma espectral el establecimiento de una función de densidad para todos lo pixeles incluidos en las áreas de entrenamiento, y se calcula los valores de probabilidad de pertenencia a una u otra categoría de información (Lillesand, Kieffer \& Chipman, 2007). En términos generales, consiste en crear zonas de isoprobabilidad alrededor de cada firma espectral y clasificar cada pixel dependiendo de su cercanía con estas. No obstante se varió el método al modificar el modo de determinar las funciones de probabilidad, en sustitución por probabilidades establecidas en forma a priori.

Figura 1. Área de estudio.

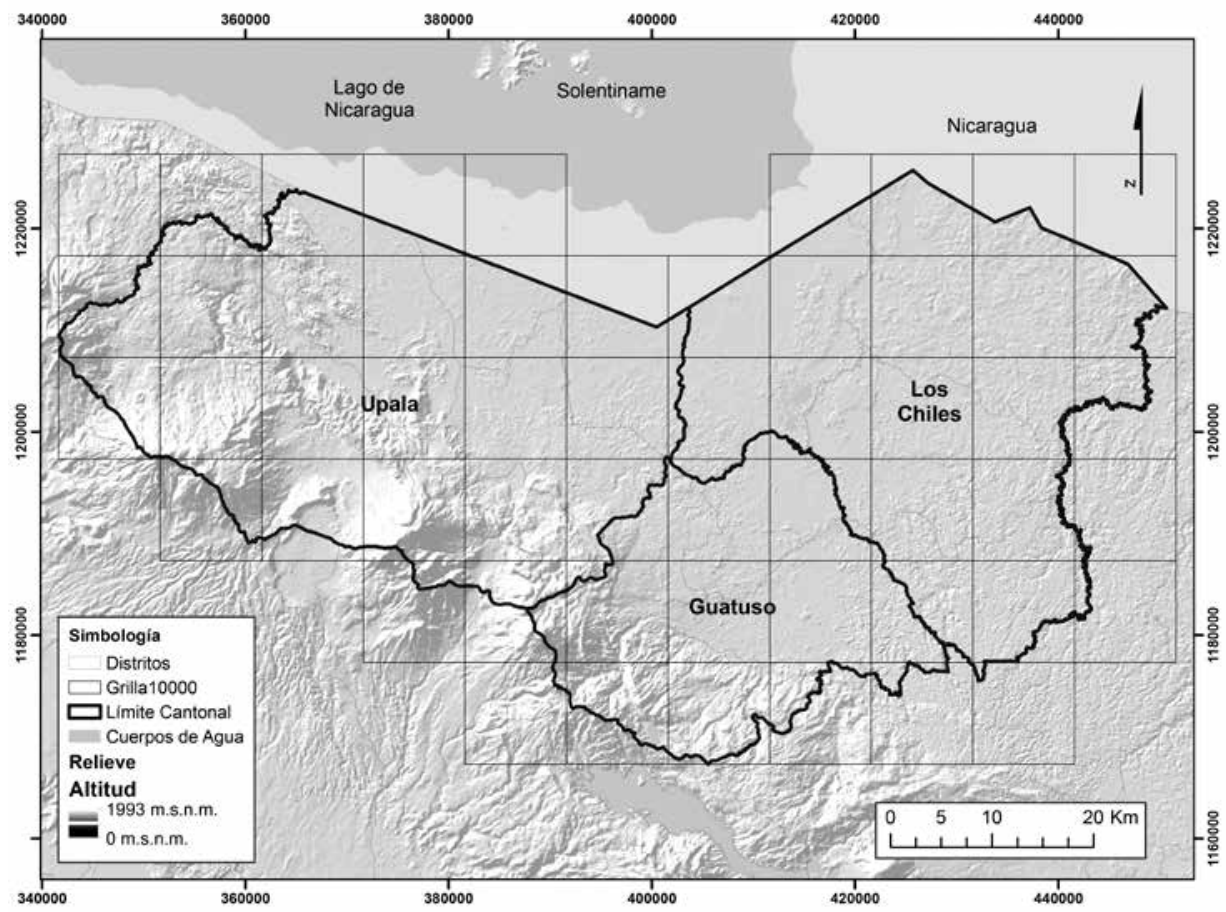

Fuente: Elaboración propia.

También, se realizó una mejora en el mosaico fotogramétrico del área de estudio. Debido a las constantes condiciones nubosas predominantes durante el año, y ocasionadas por el Efecto Föhn en las áreas cercanas 
a los volcanes Rincón de la Vieja, Tenorio y Miravalles, así como otro tipo de nubosidad presente por la influencia del Lago de Nicaragua y al efecto de sombras por la orografía. El pre-proceso consistió en reducir la incidencia de nubes y sombras, a partir de la combinación de dos imágenes con una diferencia temporal de 7 meses. La combinación se realizó a partir de la selección binaria en una cuadrícula $(1 \mathrm{~km} \times 1 \mathrm{~km}$ por sector) de las áreas con menor presencia de nubosidad y sombras. Este proceso redujo de $23,72 \%$ un a $17,3 \%$ la cobertura de nubes y sombras presentes (Figura).

Se utilizaron subconjuntos altitudinales y clinométricos en el proceso de clasificación, con el propósito de mejorar la identificación de las clases de usos presentes en el territorio (figura 4), especialmente debido a la diversidad de particularidades o heterogeneidad en la zona. Se realizaron trabajos de verificación en el terreno, que iniciaron a finales del año 2010 y se extendieron hasta mediados del año 2011.

Figura 2. Selección de áreas de menor nubosidad.
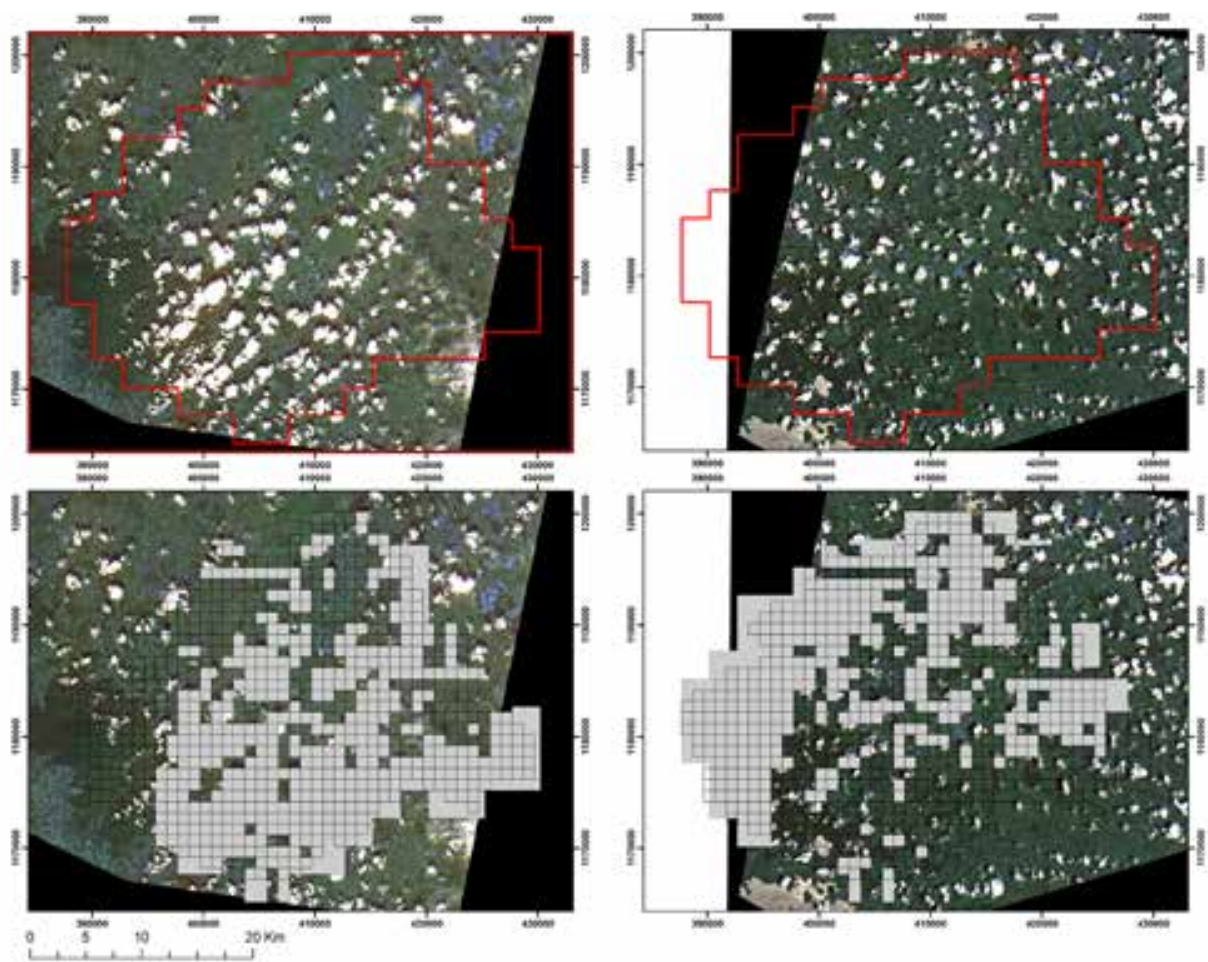

Fuente: Elaboración propia a partir de Imagen espectral RapidEye. 
Omar Barrantes Sotela, Luis Sandoval Murillo. Uso/cobertura de la tierra en los cantones de Upala, Guatuso y Los Chiles en el año 2011

DOI: http://dx.doi.org/10.15359/rgac.1-56.3

Para la sistematización de los puntos de control se utilizó un muestreo de tipo aleatorio estratificado y delimitado a zonas accesibles en el terreno. Este método tiene el propósito de adquirir información de forma homogénea, pero aleatoria en la totalidad del área estudiada (Wundram \& Löffler, 2008). Para tal efecto se generaron cinco puntos aleatorios por cuadrícula de grilla con dimensiones de $10000 \mathrm{~m}$ x $10000 \mathrm{~m}$, considerando un criterio de distancia hacia caminos, menor a $600 \mathrm{~m}$ y pendientes inferiores al $40 \%$.

Mientras que el levantamiento de información en el terreno, se realizó mediante el registro de la ficha de levantamiento estructurada con un identificador (ID), la altitud (m.s.n.m), el error del instrumento, el tipo de cobertura de uso y su localización espacial por medio del instrumento de GPS. Adicionalmente se recolecto una serie de puntos de interés, que no estaban contemplados en el muestreo, pero su registro fue importante debido a las características de esos sitios (tipo de uso, relieve, vegetación o nivel de degradación presente). Cada sitio de entrenamiento está registrado en un archivo de elemento de clase (feature class), que está asociado a un registro fotográfico (en formato panorámico), permitiendo en caso de duda aclarar la clase de uso al que pertenece el dato (Figura 3 y tabla 1). 

of Upala, Guatuso and Los Chiles in the year 2011 DOI: http://dx.doi.org/10.15359/rgac.1-56.3

Figura 3. Zona Norte-Norte: Puntos de control y de muestreo.

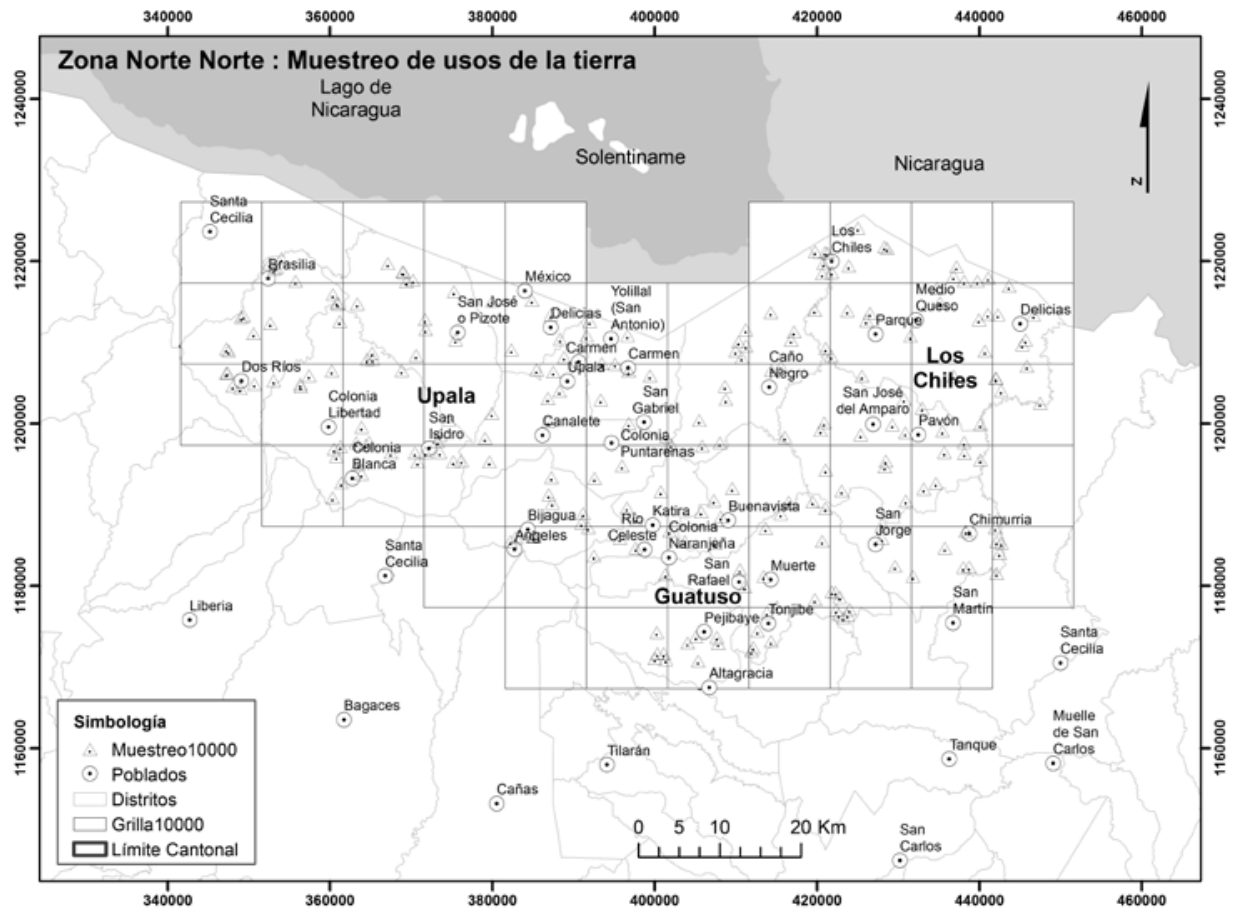

Fuente: Elaboración propia.

Tabla 1. Demostración de registro de puntos de entrenamiento.

\begin{tabular}{|c|c|c|c|c|c|c|c|c|c|}
\hline ID & Altitud & Error & Orientación & Uso & $\begin{array}{c}\text { Serie } \\
\text { Fotográfica }\end{array}$ & $\begin{array}{c}\text { N } \\
\text { Construcciones }\end{array}$ & Pendiente & Relieve & DS \\
\hline 009 & 49 & 4 & $40^{\circ} \mathrm{SE}$ & Arroz & DSC01639 & 1 & $0-3 \%$ & Plano & 3 \\
\hline
\end{tabular}

Fuente: Elaboración propia mediante levantamiento en el terreno. 
Omar Barrantes Sotela, Luis Sandoval Murillo. Uso/cobertura de la tierra en los cantones de Upala, Guatuso y Los Chiles en el año 2011

DOI: http://dx.doi.org/10.15359/rgac.1-56.3

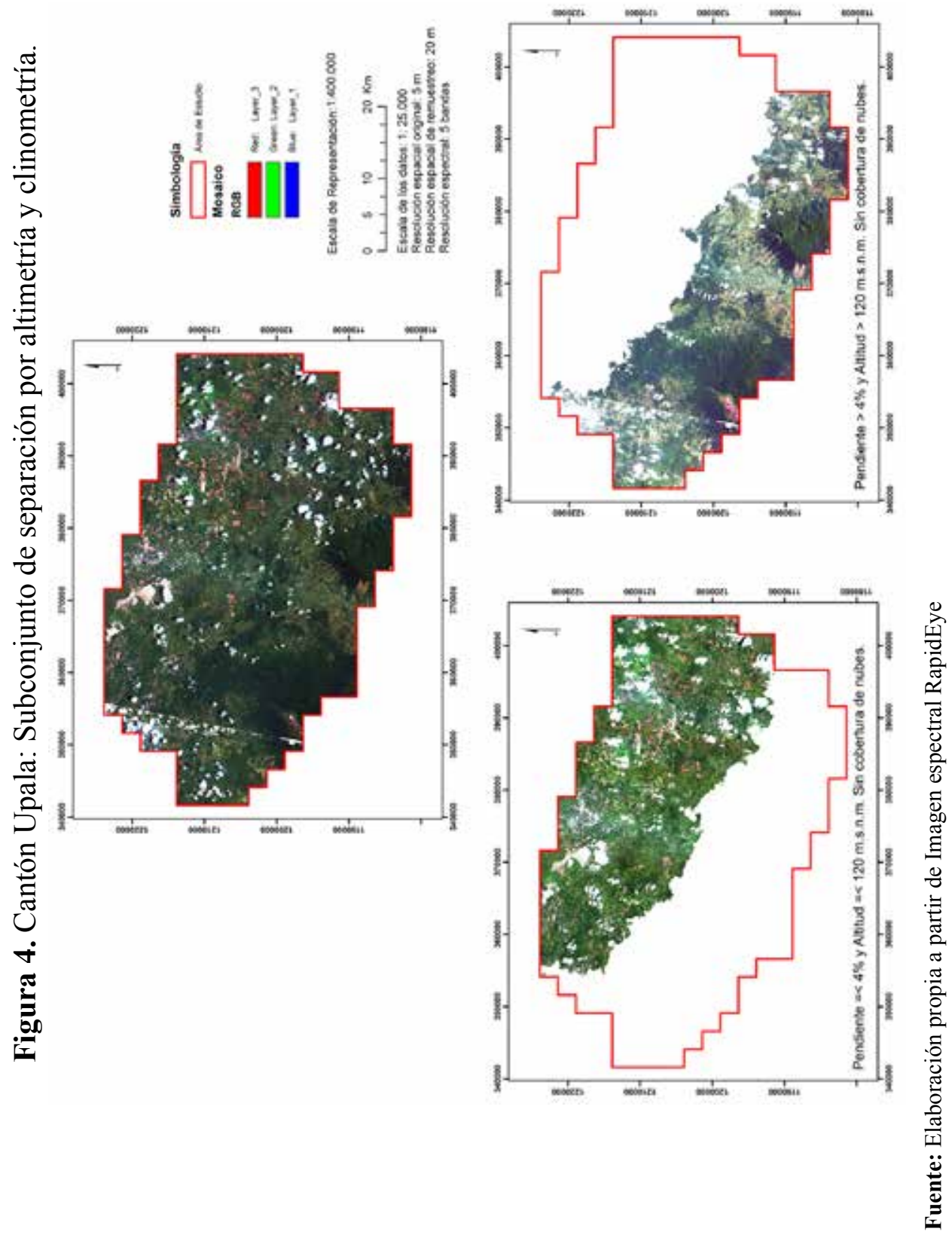


Del registro total de los sitios de entrenamiento y sitios de interés, se establecen las categorías generales utilizadas en el proceso de clasificación y posteriormente detalladas en subtipos de uso/cobertura en la etapa de post-clasificación (Ver Tabla 2).

Tabla 2. Clasificación y codificación de coberturas/uso de la tierra.

\begin{tabular}{|c|c|c|c|c|c|c|c|c|}
\hline Categoría & Código & Clase & Categoría & Código & Clase & Categoría & Código & Clase \\
\hline Forestal & $\begin{array}{l}\text { F01 } \\
\text { F02 }\end{array}$ & $\begin{array}{l}\text { Bosque } \\
\text { Denso } \\
\text { Bosque } \\
\text { Menos } \\
\text { Denso } \\
\text { Bosque de } \\
\text { Ribera } \\
\text { Plantación } \\
\text { Forestal }\end{array}$ & $\begin{array}{c}\text { Cultivos } \\
\text { Permanente }\end{array}$ & $\begin{array}{l}\text { AGP01 } \\
\text { AGP02 }\end{array}$ & $\begin{array}{l}\text { Cítrico } \\
\text { Guayaba }\end{array}$ & $\begin{array}{l}\text { Cultivos } \\
\text { Anuales }\end{array}$ & $\begin{array}{l}\text { AGA01 } \\
\text { AGA02 } \\
\text { AGA03 } \\
\text { AGA04 } \\
\text { AGA05 } \\
\text { AGA06 } \\
\text { AGA07 } \\
\text { AGA08 } \\
\text { AGA09 }\end{array}$ & $\begin{array}{l}\text { Arroz } \\
\text { Frijol } \\
\text { Yuca } \\
\text { Caña } \\
\text { Piña } \\
\text { Maíz } \\
\text { Ñame } \\
\text { Ayote } \\
\text { Plátano } \\
\end{array}$ \\
\hline \multirow{2}{*}{$\begin{array}{c}\text { Cuerpo de } \\
\text { Agua }\end{array}$} & CA01 & Río & \multirow{2}{*}{ Pecuario } & P01 & $\begin{array}{l}\text { Pasto con } \\
\text { Árboles }\end{array}$ & $\begin{array}{c}\text { Terreno } \\
\text { Descubierto }\end{array}$ & $\begin{array}{l}\text { TD01 } \\
\text { TD02 }\end{array}$ & $\begin{array}{l}\text { Preparación } \\
\text { Cultivo } \\
\text { Proceso } \\
\text { Natural }\end{array}$ \\
\hline & $\begin{array}{l}\mathrm{CA02} \\
\mathrm{CA03}\end{array}$ & $\begin{array}{l}\text { Lago o } \\
\text { Laguna } \\
\text { Embalse o } \\
\text { Canal }\end{array}$ & & $\begin{array}{l}\mathrm{P} 02 \\
\mathrm{P} 03\end{array}$ & $\begin{array}{l}\text { Pasto } \\
\text { Pasto } \\
\text { Mejorado }\end{array}$ & Urbano & U1 & $\begin{array}{l}\text { Centro } \\
\text { Poblado }\end{array}$ \\
\hline
\end{tabular}

Fuente: Elaboración propia resultante del proceso de codificación.

Para la evaluación del proceso de Clasificación Supervisada, el método más común utilizado para determinar la precisión del clasificador, es aquel que se basa en el registro de sitios específicos, que son evaluados de acuerdo a una matriz de confusión o error con composición de valores ( $\mathrm{n} x \mathrm{n}$, donde $\mathrm{n}$ es cada tipo de cobertura) (Ellis et al., 2009; Foody, 2009; Rosenfield, 1986; Ruelland, Dezetter, Puech \& Ardoin-Bardin, 2008; Strahler et al., 2006).

Debido a la dificultad de evaluar la precisión de la totalidad del área mapeada, la valoración de la precisión de la clasificación se realizó por medio de un diseño de muestreo aleatorio. En orden de garantizar y realizar generalizaciones creíbles en el mapeo del área de estudio mediante una muestra, es necesario que el diseño de muestreo sea el más imparcial y representativo. El tamaño de la muestra requerida es de suma importancia para establecer una valoración de precisión robusta (Foody, 2009). En esta investigación se optó por un muestreo simple aleatorio, con un 
Omar Barrantes Sotela, Luis Sandoval Murillo. Uso/cobertura de la tierra en los cantones de Upala, Guatuso y Los Chiles en el año 2011

DOI: http://dx.doi.org/10.15359/rgac.1-56.3

nivel de confianza del $98 \%\left(Z_{\alpha}=2.054\right)$, con una probabilidad de éxito del $50 \%(\mathrm{p})$ y un error de estimación $(\mathrm{d})$ del $10 \%$ considerando el presupuesto económico y temporal disponible para el trabajo de campo, lo que da como resultado un tamaño de muestra para la validación (n) de 106 sitios.

$$
n=\left(\frac{Z * \sqrt{p * q}}{d}\right)^{2}=\left(\frac{2.054 * \sqrt{0.5 * 0.5}}{0.1}\right)^{2}=105.4729 \approx 106
$$

Adicionalmente, mediante un análisis de similitud de espectro y similitud visual, los sitios de control de validación y algunos sitios de interés se replicaron a distancias de 5 a $10 \mathrm{~m}$ y sirvieron como base ampliada para la elaboración de una matriz de concordancia, pero con un diseño de muestreo estratificado de las categorías de cobertura y uso de la tierra, este tipo de metodología se considera como dirigida (tamaño y distancia constante del conjunto de muestra).

Para analizar la matriz de confusión, se usa el indicador estadístico de concordancia Kappa (Cohen, 1960), el cual determina el grado de concordancia que existe por encima del acuerdo esperado al azar, y que básicamente se puede interpretar como el peso que de la máxima concordancia posible tiene en los acuerdos observados. Esto supone, establecer la correspondencia entre los resultados de la clasificación supervisada y el uso/cobertura registrado en terreno, así como la concordancia que se debe esperar por generación aleatoria. Es decir, se delimita el grado de ajuste debido sólo a la exactitud de la clasificación, prescindiendo del causado por factores aleatorios. El índice tiene un rango de 0.0 (no hay correlación aparente) a 1.0 (indica correlación perfecta). Según Landis \& Koch (1977), sí el coeficiente Kappa es mayor a 0,8 se puede afirmar que es poco probable que la clasificación supervisada realizada sea obtenida por azar.

\section{Índice Kappa:}

$$
K=\frac{p-p_{c}}{1-p_{c}}
$$




$$
K=\frac{N \sum_{i=1}^{r}\left(\chi_{i i}\right)-\sum_{i=1}^{r}\left(\chi_{i+} * \chi_{+i}\right)}{N^{2} \sum_{i=1}^{r}\left(\chi_{i+} * \chi_{+i}\right)}
$$

Tabla 3. Escala de valoración de Índice Kappa.

\begin{tabular}{|c|c|}
\hline Valor de Índice Kappa & Fuerza de la concordancia \\
\hline 0 & Sin concordancia \\
\hline$<0.20$ & Insignificante \\
\hline $0.21-0.40$ & Discreto \\
\hline $0.41-0.60$ & Moderado \\
\hline $0.61-0.80$ & Sustancial \\
\hline $0.81-1.00$ & Casi perfecto \\
\hline
\end{tabular}

Fuente: (Landis \& Koch, 1977)

Al aplicar un nivel de confianza al 95\%, se calcula un intervalo de confianza usando la formula genérica:

$$
C I=K a p p a \pm 1.96 * \operatorname{Std} \text { Error }
$$

Es importante aclarar, que si bien el índice Kappa es una de las métricas más utilizadas para establecer la precisión del método de clasificación, el mismo presenta una serie de limitaciones y contradicciones ampliamente abordadas en otras publicaciones (Foody et al., 2005; Foody, 2008; Jung, 2003; Pontius \& Millones, 2011; Strahler et al., 2006). Las críticas más frecuentes son: 1) la corrección de la probabilidad de concordancia aleatoria es una métrica que no describe la precisión que el usuario del mapa puede encontrar al hacer uso del mismo; 2) en casos no concordantes, no considera la distancia o localización de las clases que se comparan, y el cual debe ser un parámetro a considerar en la precisión espacial. Está investigación busca reportar este valor con propósitos meramente descriptivos, y se considera de mayor utilidad la consignación de las matrices de concordancia. 
Omar Barrantes Sotela, Luis Sandoval Murillo. Uso/cobertura de la tierra en los cantones de Upala, Guatuso y Los Chiles en el año 2011

DOI: http://dx.doi.org/10.15359/rgac.1-56.3

\section{Resultados}

En el proceso de clasificación supervisada, se usó la información del terreno en 192 sitios de entrenamiento, así como información complementaria en 163 lugares (ver tabla 4). El rango de error de localización en las mediciones del GPS oscilo entre 2 y $6 \mathrm{~m}$ en cada registro, con un error promedio de $3.96 \mathrm{~m}$ y desviación estándar de $0.93 \mathrm{~m}$. Lo que facilitó la identificación y asignación de clases, al establecer las firmas espectrales generales o representativas para cada categoría mediante el análisis de las bandas en los sitios visitados.

Las categorías de uso y cobertura forestal en escala general, fueron muy fáciles de clasificar de manera agrupada. Sin embargo, al segregar cuantitativamente la clase forestal en categorías de vegetación específica mediante los valores de reflectancia, resulto ser poco representativo e ineficiente en los casos particulares. En las categorías (bosque denso, bosque menos denso, bosque de ribera, plantación forestal y pasto con árboles) prevalece un patrón espectral difuso difícil de identificar o agrupar, y que además presentan una gran semejanza de tonos, texturas y formas. Lo que aumenta las posibilidades de incluir valores de pixeles que no pertenecen a una clase, tal como lo afirma (Huising, 1993), y que se evidencia en los datos de la matriz de concordancia, así como en el resultado de la asignación de precisión del clasificador (Índice Kappa).

Tabla 4. Puntos de entrenamiento y de interés

\begin{tabular}{|lcccc|}
\hline \multicolumn{1}{|c}{ Cantón } & $\begin{array}{c}\text { Cantidad de } \\
\text { muestra }\end{array}$ & $\begin{array}{c}\text { Puntos } \\
\text { recolectados }\end{array}$ & $\begin{array}{c}\text { \% de Muestra } \\
\text { registrada }\end{array}$ & $\begin{array}{c}\text { Puntos de } \\
\text { interés }\end{array}$ \\
\hline Upala & 98 & 76 & $77,55 \%$ & 70 \\
Guatuso & 46 & 39 & $84,78 \%$ & 0 \\
Los Chiles & 91 & 77 & $84,62 \%$ & 93 \\
\hline Total & $\mathbf{2 3 5}$ & $\mathbf{1 9 2}$ & $\mathbf{8 1 . 7 0 \%}$ & $\mathbf{1 6 3}$ \\
\hline
\end{tabular}

Fuente: Elaboración propia.

El índice kappa puntual calculado en el proceso de clasificación supervisada para el muestreo aleatorio simple fue de $\mathrm{K}=0.4393$ en un intervalo de confianza del $95 \%$ entre (0.3268 a 0.5518$)$, por lo que se considera que la precisión del clasificador según la evaluación o criterio de precisión es de concordancia moderada. Mientras que con el muestreo estratificado, 
se obtuvo un $\mathrm{K}=0.5909$ en un intervalo de confianza del $95 \%$ entre (0.4964 a 0.6854), lo cual también indica concordancia moderada.

Universalmente, se sugiere que el clasificador debe presentar al menos un $85 \%$ de precisión en la asignación correcta de categorías (Anderson, Hardy, Roach, Witmer, \& Peck, 1976), no obstante como sugiere (Foody, 2008; Olofsson et al., 2014), este tipo de consideración puede ser inapropiada, especialmente si se considera un mosaico de paisaje heterogéneo en el cual pueden existir una relatividad en el detalle de las clases o categorías y que según (Foody, 2008; Laba et al., 2002; Pontius \& Millones, 2011; Wundram \& Löffler, 2008; Zhang \& Chen, 2014) en muchos casos es irreal, tal y como ocurre en la matriz de uso/cobertura de la tierra del área de estudio.

Tabla 5. Matriz de confusión de muestra aleatoria simple: Clasificador (CS) entre Clase Observada (CO).

\begin{tabular}{|c|c|c|c|c|c|c|c|c|c|c|c|c|c|}
\hline $\mathrm{CS}$ & $\begin{array}{c}\text { AGA } \\
01\end{array}$ & $\begin{array}{c}\text { AGA } \\
05\end{array}$ & $\begin{array}{c}\text { AGA } \\
06\end{array}$ & $\begin{array}{c}\text { AGP } \\
01\end{array}$ & $\begin{array}{c}\text { AGP } \\
04\end{array}$ & F01 & F02 & F03 & F04 & P01 & P02 & P03 & Total \\
\hline AGA01 & 7 & 0 & 1 & 1 & 0 & 0 & 0 & 0 & 0 & 1 & 0 & 0 & 10 \\
\hline AGA05 & 0 & 14 & 0 & 0 & 0 & 0 & 0 & 0 & 0 & 0 & 0 & 0 & 14 \\
\hline AGA06 & 0 & 0 & 0 & 0 & 0 & 0 & 0 & 0 & 0 & 0 & 0 & 0 & 0 \\
\hline AGP01 & 0 & 0 & 0 & 9 & 0 & 0 & 0 & 0 & 0 & 1 & 0 & 0 & 10 \\
\hline AGP04 & 0 & 0 & 0 & 0 & 0 & 0 & 0 & 0 & 0 & 0 & 0 & 0 & 0 \\
\hline F01 & 0 & 0 & 0 & 0 & 0 & 0 & 5 & 1 & 0 & 0 & 0 & 0 & 6 \\
\hline F02 & 0 & 0 & 0 & 0 & 0 & 0 & 1 & 0 & 1 & 0 & 0 & 0 & 2 \\
\hline F03 & 0 & 0 & 0 & 0 & 0 & 0 & 1 & 0 & 0 & 0 & 0 & 0 & 1 \\
\hline F04 & 0 & 0 & 0 & 0 & 0 & 0 & 0 & 0 & 3 & 0 & 0 & 0 & 3 \\
\hline P01 & 3 & 0 & 0 & 2 & 0 & 0 & 8 & 1 & 1 & 13 & 11 & 1 & 40 \\
\hline P02 & 0 & 2 & 0 & 1 & 1 & 0 & 0 & 0 & 0 & 5 & 8 & 2 & 19 \\
\hline $\mathrm{P} 03$ & 0 & 0 & 0 & 0 & 0 & 0 & 0 & 0 & 0 & 0 & 0 & 0 & 0 \\
\hline Total & 10 & 16 & 1 & 13 & 1 & 0 & 15 & 2 & 5 & 20 & 19 & 3 & 105 \\
\hline
\end{tabular}


Omar Barrantes Sotela, Luis Sandoval Murillo. Uso/cobertura de la tierra en los cantones de Upala, Guatuso y Los Chiles en el año 2011

DOI: http://dx.doi.org/10.15359/rgac.1-56.3

Tabla 6. Matriz de confusión de muestra estratificada: Clasificador (CS) entre Clase Observada (CO).

\begin{tabular}{|c|c|c|c|c|c|c|c|c|c|c|c|c|c|}
\hline $\mathrm{CS}$ & $\begin{array}{c}\text { AGA } \\
01\end{array}$ & $\begin{array}{c}\text { AGA } \\
05\end{array}$ & $\begin{array}{c}\text { AGA } \\
06\end{array}$ & $\begin{array}{c}\text { AGP } \\
01\end{array}$ & $\begin{array}{c}\text { AGP } \\
04\end{array}$ & F01 & F02 & F03 & F04 & P01 & P02 & P03 & Total \\
\hline AGA01 & 6 & 0 & 0 & 1 & 0 & 0 & 0 & 0 & 0 & 1 & 2 & 0 & 10 \\
\hline AGA05 & 0 & 10 & 0 & 0 & 0 & 0 & 0 & 0 & 0 & 0 & 0 & 0 & 10 \\
\hline AGA06 & 0 & 0 & 5 & 0 & 0 & 0 & 0 & 0 & 0 & 3 & 2 & 0 & 10 \\
\hline AGP01 & 0 & 0 & 0 & 6 & 0 & 0 & 3 & 0 & 0 & 1 & 0 & 0 & 10 \\
\hline AGP04 & 0 & 0 & 0 & 0 & 2 & 0 & 4 & 0 & 0 & 4 & 0 & 0 & 10 \\
\hline F01 & 0 & 0 & 0 & 0 & 0 & 7 & 2 & 1 & 0 & 0 & 0 & 0 & 10 \\
\hline F02 & 0 & 0 & 0 & 0 & 0 & 0 & 9 & 0 & 1 & 0 & 0 & 0 & 10 \\
\hline F03 & 0 & 0 & 0 & 0 & 0 & 0 & 2 & 8 & 0 & 0 & 0 & 0 & 10 \\
\hline F04 & 0 & 0 & 0 & 0 & 0 & 0 & 0 & 7 & 3 & 0 & 0 & 0 & 10 \\
\hline P01 & 0 & 0 & 0 & 0 & 0 & 0 & 0 & 0 & 0 & 8 & 1 & 1 & 10 \\
\hline P02 & 0 & 0 & 0 & 0 & 0 & 0 & 0 & 0 & 0 & 0 & 8 & 2 & 10 \\
\hline $\mathrm{P} 03$ & 0 & 0 & 0 & 0 & 0 & 0 & 0 & 0 & 0 & 0 & 7 & 3 & 10 \\
\hline Total & 6 & 10 & 5 & 7 & 2 & 7 & 20 & 16 & 4 & 17 & 20 & 6 & 120 \\
\hline
\end{tabular}

Fuente: Elaboración propia. Códigos según Tabla 2.

Las clases que generaron la mayoría de los valores falsos positivos (errores de tipo II) en el clasificador fueron: pasto con árboles, pasto, bosque denso y bosque menos denso. Otras asignaciones de clases que mostraron gran variabilidad son las categorías de bosque denso, denso, palma y arroz.

Lo que puede ser explicado por deficiencias o errores sistemáticos en la asignación de las clases, identificación en el terreno, relación de escala de la imagen (clasificador/validación) y el tamaño de muestra en el diseño de validación. En el diseño de muestra por selección aleatoria, algunas categorías de cobertura/uso no fueron validadas en el terreno por el instrumento y al contrario un $38.1 \%$ de los sitios de validación se recargaron en una sola categoría específica y que coincide, además, en una clase con patrón espectral difuso, lo que limita la fuerza explicativa significativa del estimador de precisión. Mientras que con un muestreo estratificado, se obtienen mejores resultados, pero debe considerarse un tamaño mayor de sitios, tal y como lo afirma (Foody, 2009). A su vez, es importante indicar, que en la Tabla 5 ocurren más casos por omisión en la asignación de las categorías y en la Tabla 6 al contrario son más casos por comisión. 
Gráfico 1. Comisiones y Omisiones según Matriz de Concordancia. Caso A: Muestreo Aleatorio, Caso B: Muestreo Estratificado.
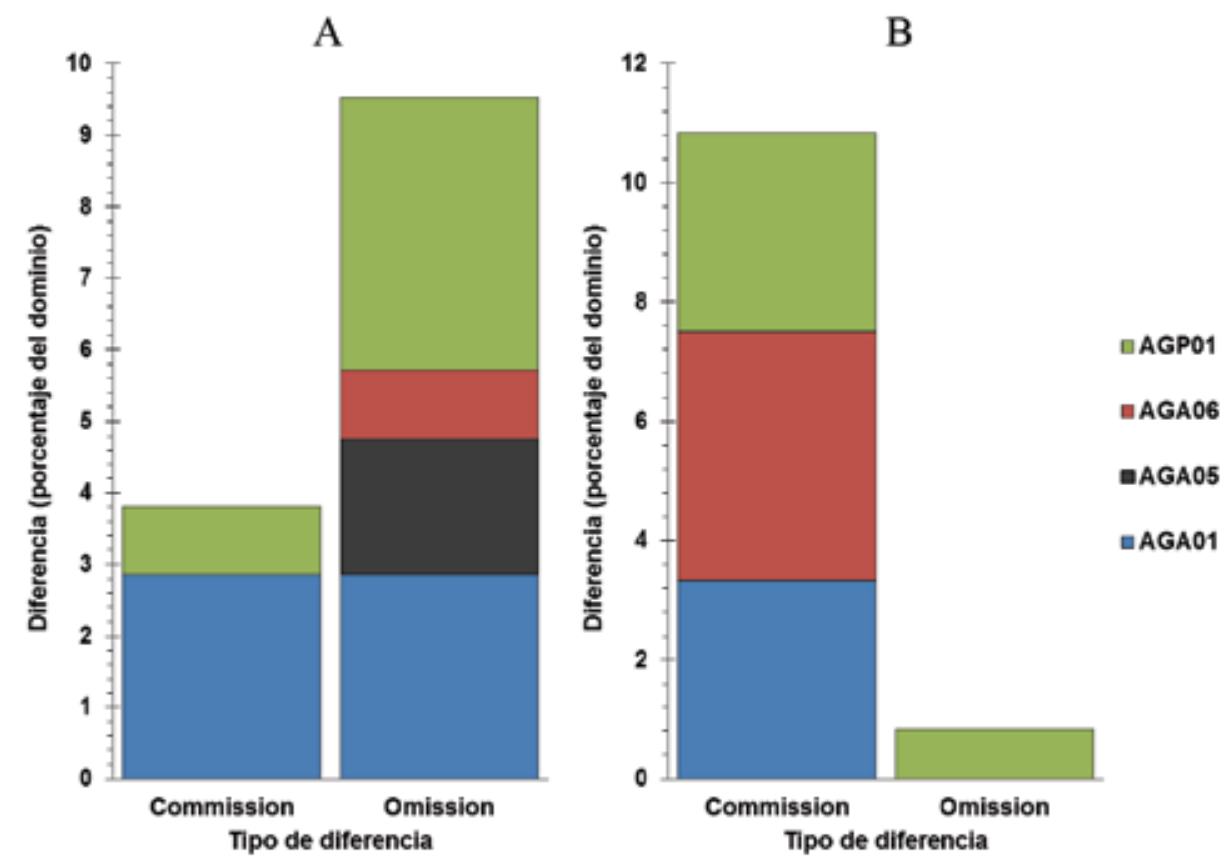

Fuente: Elaboración propia.

Al cuantificar mediante una matriz la distancia aquellos puntos no concordantes $^{3}$ con respecto a la clase que según la verificación de campo debió asignarse, se registró un rango de error normalizado que iba desde los 20 a $50 \mathrm{~m}$. No obstante, en los casos extremos detectados, las distancias se aproximaban con un mínimo de $2 \mathrm{~km}$. Al indagar sobre estos casos específicos, se detectó que la clase había cambiado entre el tiempo que transcurrió de la etapa de clasificación y la de validación, principalmente, a la alta rotación de los cultivos ( 3 a 4 meses) o al incremento de la extensión de los mismos. Este tipo de mediciones acciones puede ser una buena aproximación para establecer el error de reasignación espacial (allocation error).

En un proceso post-clasificación, que se basa en la corrección por fotointerpretación mediante el uso de puntos de identificación, mejoraron considerablemente la asignación de las categorías de análisis con mayores

3 Se obviaron las clases forestales que no coincidieron con otras tipologías de cobertura/uso forestal. 
Omar Barrantes Sotela, Luis Sandoval Murillo. Uso/cobertura de la tierra en los cantones de Upala, Guatuso y Los Chiles en el año 2011

DOI: http://dx.doi.org/10.15359/rgac.1-56.3

dificultades de identificación o de catalogación. De igual forma este criterio fue empleado en otras clases de uso/cobertura, con el propósito de evitar asignaciones erróneas. Por lo tanto, se considera que después del proceso de clasificación y verificación, emplear un ajuste en la asignación e identificación de usos mediante un criterio de experto, con base en la información adquirida del área de estudio con el transcurso del tiempo y la experiencia de campo, se obtienen resultados muy robustos en la preparación de cartografía temática.

En términos generales los usos/cobertura de la tierra del área de estudio, presentan una configuración heterogénea en la distribución (Figura) y tamaño (Gráfico 2). A continuación se describen los resultados obtenidos por clases de cobertura/uso de la tierra.

Figura 5. Sector Los Chiles: usos/coberturas de la tierra.

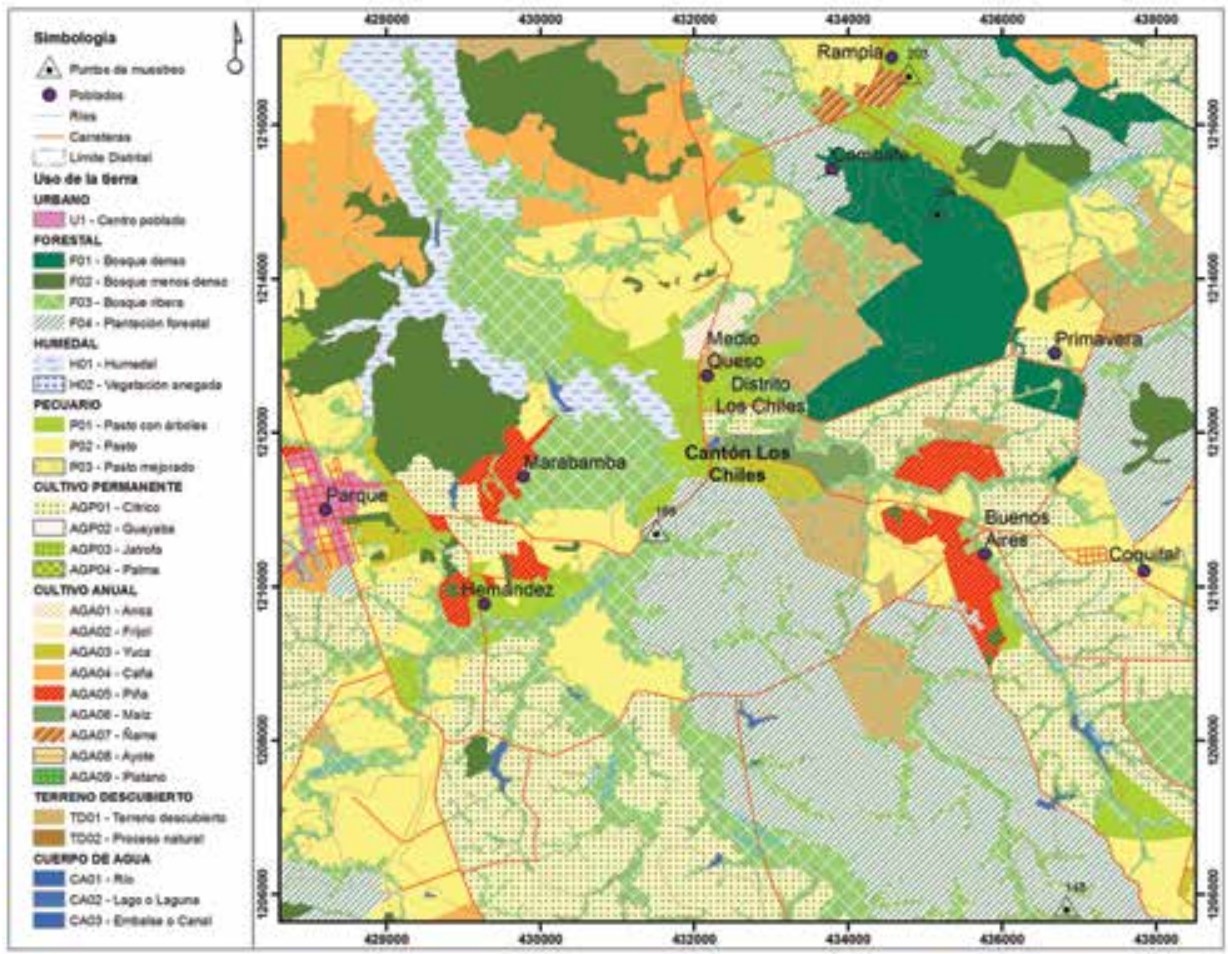

Fuente: Elaboración propia a partir del procesamiento de imágenes satelitales. 


\section{Bosque denso}

La cobertura de bosque denso mantiene un predominio en el sector cercano a la Cordillera Volcánica de Guanacaste. La alta concentración de bosque denso se relaciona a la presencia de Parques nacionales como el Parque Nacional Rincón de la Vieja, Parque Nacional Volcán Tenorio, Parque Nacional Guanacaste y Zona Protectora Miravalles. Sin embargo, las áreas de planicie y asociadas a los humedades de Las Camelias, Caño Negro, Caño Blanco y Caño Ciego y Medio Queso, así como el área cercana que trascurre longitudinalmente al Corredor Fronterizo Norte, la presencia de bosque denso es escaza y fragmentada, y de manera teórica se pueden definir como relictos. Producto de la ocupación extensiva de la actividad agrícola, misma que continúa y afecta los pequeños fragmentos de bosque, localizados principalmente en las zonas aledañas. Aspecto que se evidencia al estar continuos a usos agrícolas como arroz y piña, y que limita el proceso de regeneración natural (Barrantes, 2012).

Gráfico 2. Zona Norte: Superficie de usos de la tierra [ha]

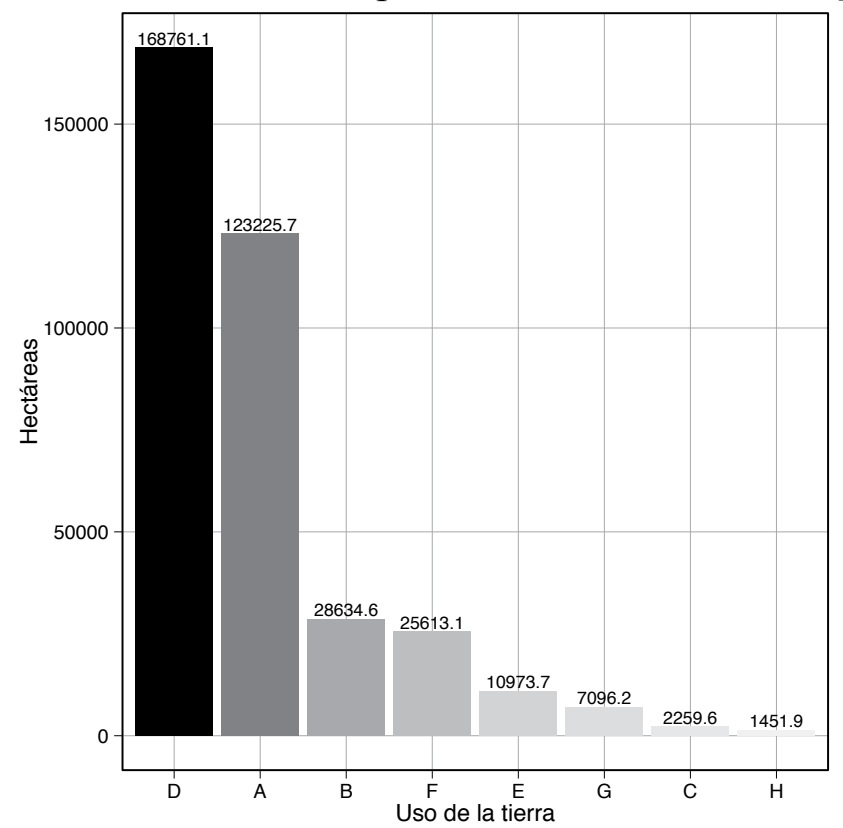

A: Forestal; B: Humedal; C: Cuerpo de agua; D: Pecuario; E: Cultivo permanente; F: Cultivo anual; G: Terreno descubierto; H: Uso urbano

Fuente: Elaboración propia. 
Omar Barrantes Sotela, Luis Sandoval Murillo. Uso/cobertura de la tierra en los cantones de Upala, Guatuso y Los Chiles en el año 2011

DOI: http://dx.doi.org/10.15359/rgac.1-56.3

\section{Bosque menos denso}

El bosque menos denso, presenta un extensión similar al bosque denso, solo que esta clase se distribuye en áreas de altitudes medias y bajas, también son cercanas a las actividades agropecuarias, mismas que generan gran presión y sustitución de la cobertura boscosa por cultivos, (Ver mapa 1). Se consideran como pequeños remanentes con alto potencial para ser regenerados.

\section{Plantaciones forestales}

Con respecto a la plantación forestal, se localizan en fincas extensas (figura 6), algunas de las cuales se encuentran regidas o reglamentadas por políticas medioambientales del país. Los tipos de plantaciones predominantes son de Teca (Tectona grandis) y Melina (Gmelina arborea). Las plantaciones de Teca son altamente productivas en sitios bien drenados con un contenido de arcilla inferior al 35\%, valores de $\mathrm{pH}$ de 6.0-6.9, y un moderado contenido de calcio en el suelo como lo reporta (Sage, De Camino, \& Alfaro, 2002; Ugalde, 1997). Mientras que la Melina prospera en áreas ligeramente inundadas pero drenados, suelos profundos con $\mathrm{pH}$ entre 5.0-6.0 (Rojas Rodríguez et al., 2004). 
Figura 6. Sitos de muestreos. Plantación forestal y cítricos.
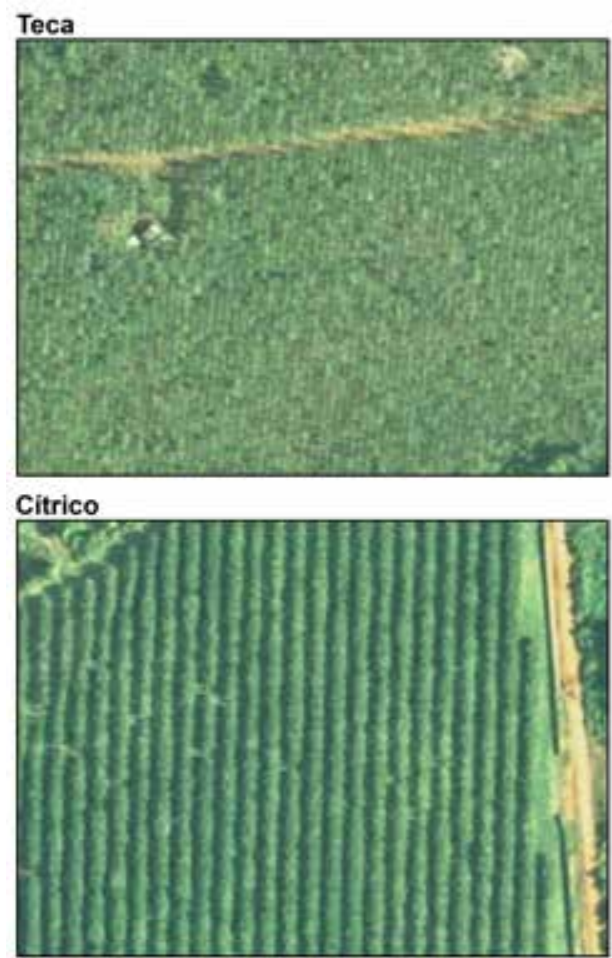

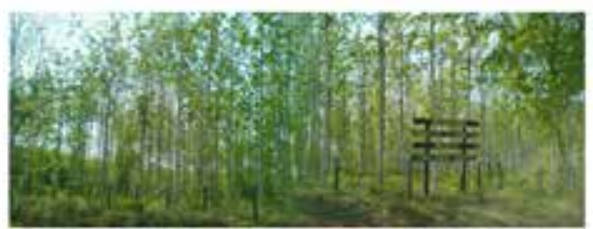

Uso: Teca

Número de construcción: 0

Pendiente: $0-3 \%$

Relieve: Planicie

DS: $1-2$

Vegetación: Semi caducifolio

Estrato: arbóreo

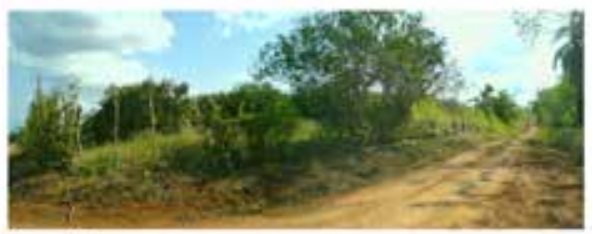

Uso: Citrico

Nûmero de construcción: 0

Pendiente: $0-3 \%$

Retieve: Planicie

DS: $1-2$

Vegetación: Semi caducifolio

Estrato: arbóreo

\section{Bosque de ribera}

Se localiza en los alrededores de ríos u otros cursos de agua, en gradación de catena (Wong, Sáenz, \& Carrillo, 1999). Se extiende lateralmente desde el cauce activo hacia terreno elevado, que incluye la planicie de inundación activa y las terrazas adyacentes (Naiman, Fetherston, Mckay, \& Chen, 1998). Además incorpora bosques remanentes y vegetación con estructura simple dominada por especies pioneras cerca de los cauces (Barrantes, 2012). En la Zona Norte - Norte, estas áreas representan un $5.47 \%$ de la superficie total y se encuentra bajo una gran presión, debido al desarrollo de canales de irrigación y de la tala de árboles, actividad vinculada a la ocupación y extensión de cultivos, entre los que destacan el arroz y piña. 
Omar Barrantes Sotela, Luis Sandoval Murillo. Uso/cobertura de la tierra en los cantones de Upala, Guatuso y Los Chiles en el año 2011

DOI: http://dx.doi.org/10.15359/rgac.1-56.3

\section{Humedales}

Según la definición del Decreto Ejecutivo 34433 Reglamento a la Ley de Biodiversidad, son áreas geográficas que contienen ecosistemas de importancia nacional con dependencia de regímenes acuáticos, naturales o artificiales, permanentes o temporales, lénticos o lóticos, dulces, salobres o salados, hasta seis metros de profundidad en marea baja, cuya función principal es la protección de dichos ecosistemas para asegurar el mantenimiento de sus funciones ecológicas y la provisión de bienes y servicios ambientales.

En esta investigación, se subclasifican en: humedales (solo espejo de agua) y humedales con predominancia de algún tipo de vegetación (vegetación abnegada). En su totalidad conforman un $8.14 \%$ de la superficie de la Zona. Los principales sistemas de humedales son: Humedal Caño Negro que por sus características de flora y fauna es considerado de interés mundial, por servir de albergue a una gran variedad de especies migratorias y en peligro de extinción, acciones que le otorga la declaración de sitio RAMSAR.

En el proceso de verificación de campo se observó, que en el Refugio de Vida Silvestre Caño Negro, Humedal de Medio Queso y sistemas asociados, existe invasión a las áreas de protección, la corta de árboles, sin autorización de la Administración Forestal del Estado, así como la extracción de agua para la implementación de cañales de irrigación artesanales, para el desarrollo de actividades socio-económicas de monocultivo, que alteran la estructura y composición florística y faunística, y los volúmenes promedio del nivel de agua.

\section{Cuerpos de agua}

Una de las particularidades que caracterizan la Zona Norte - Norte, es la existencia de importantes sistemas de cuerpos de agua continentales como lagunas, embalses y canales. Estas unidades son determinantes en las actividades productivas como la ganadería, la agricultura y el turismo; que significan la principal fuente de ingresos de la población de la región. Es ese contexto, los cuerpos de agua conforman el $0,7 \%$ de la superficie terrestre y se ubican de forma dispersa por todo el territorio. Los más importantes están asociados a los sistemas de humedales de Caño Negro y Medio Queso, así como a la laguna cratérica Cote. Esta clase se considera subestimada con respeto a su superficie, debido a que es una clase que es cubierta u oculta por otras, por ejemplo el bosque de ribera. 


\section{Pastos}

La cobertura de pastos (mejorados, con árboles y sin árboles), tiene una función complementaria y estratégica de repasto para las actividades de ganadería, centrándose en la producción de ganadería de doble propósito (leche - carne), así como de descanso y rotación para la actividad agrícola. Tienen una distribución dispersa y ocupan aproximadamente un $0.25 \%, 31.86 \%$ y $13.74 \%$ respectivamente.

\section{Cultivos}

La categoría de cultivos abarca el $29.2 \%$ de la superficie de la Zona Norte - Norte y están distribuidos en las zonas de moderada y baja pendiente. Los cultivos anuales más predominantes son piña ${ }^{4}$, arroz, yuca, frijol, ñame y maíz. Mientras que los cultivos permanentes característicos son los cítricos (naranja) y caña de azúcar.

El cultivo de piña amerita una especial atención, ya que si bien ha generado un importante incremento en la asignación de empleos en la zona pero que a nivel ambiental provocan un acelerado deterioro de recursos como el suelo, según (Acuña, 2006). En los piñales el suelo se mantiene completamente expuesto y se emplea mucho agroquímico, lo que hace suponer un impacto ambiental severo.

\section{Área Urbana}

Las áreas urbanas se conforman en usos residenciales comerciales, acompañados de los servicios públicos institucionales, seguido por el comercio y usos comunitarios recreativos. Los espacios urbanos constituyen un apoyo al desarrollo de las actividades agropecuarias, las cuales son predominantes, facilitando los insumos requeridos para su funcionamiento óptimo. En las principales aglomeraciones urbanas son las cabeceras de cantón y distrito, destacando los centros poblados de Upala, Bijagua, San José (Pizote), San Isidro, Colonia Puntarenas, San Rafael, Katira, Buena Vista, Cabanga, Los Chiles, Pavones El Parque y Caño Negro. Esta categoría comprende el $0.39 \%$ de la superficie del territorio.

\footnotetext{
4 Se considera al cultivo de Piña como anual, debido a su extensión y al uso intensivo de agroquímicos.
} 
Omar Barrantes Sotela, Luis Sandoval Murillo. Uso/cobertura de la tierra en los cantones de Upala, Guatuso y Los Chiles en el año 2011

DOI: http://dx.doi.org/10.15359/rgac.1-56.3

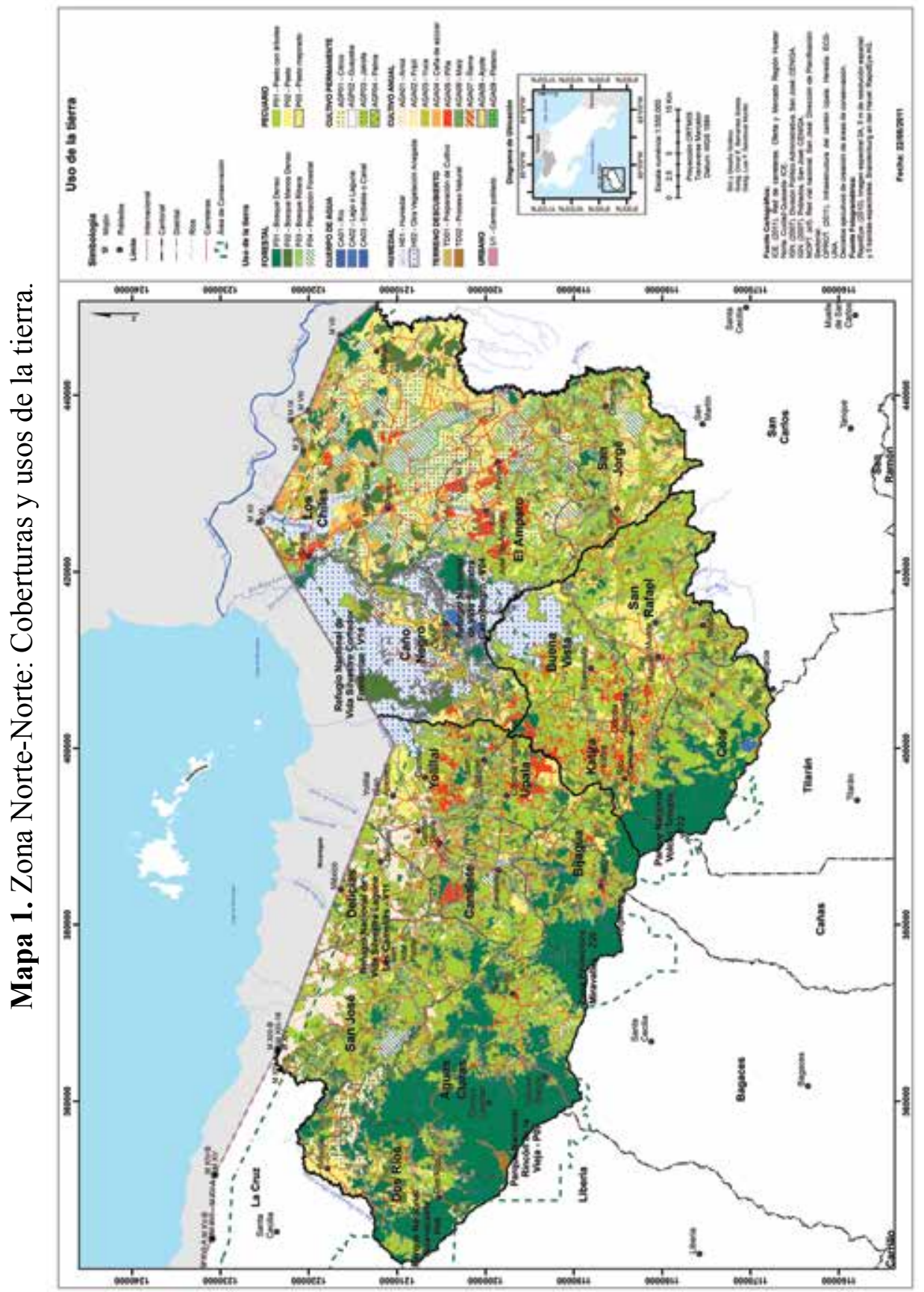




\section{Conclusión}

La elaboración de una metodología simple pero eficiente para obtener una cobertura de información de Usos de la Tierra para la Zona NorteNorte de Costa Rica. El muestreo parcial estratificado aleatorio para la generación de los sitios de entrenamiento, mejoró la distribución de recolección de información en el área de estudio, lo que garantizó el registro homogéneo en zona de gran extensión geográfica. Otro aspecto importante, fue que al considerar la accesibilidad al sitio de entrenamiento, se evitan dificultades como traspasar propiedades privadas o de acceso peligroso para el investigador.

La parcialización evita determinar correctamente la probabilidad de visitar un sitio. Se debe destacar que la generación de subconjuntos en un mosaico, a pesar de ser una labor complicada en la escogencia de los parámetros de delimitación, mejora la clasificación supervisada en clases que presentan un bajo grado de separabilidad espectral y favorece el estudio de áreas con características específicas, por ejemplo: zonas agrícolas a baja altitud / áreas verdes con favorables condiciones de recarga hídrica.

La elaboración de una cobertura de Usos de la Tierra actualizada es fundamental para ser empleada en la propuesta de un ordenamiento territorial más acorde con la realidad de estos cantones, al funcionar como un inventario o diagnóstico básico de los usos presentes y entender como los mismos esta distribuidos.

\section{Agradecimientos}

Los autores desean expresar las gracias a los municipios de Upala, Guatuso y Los Chiles, por la asistencia brindada, así como al equipo técnico de la ECG-UNA vinculado en la realización de las propuestas técnicas de Plan Regulador de la Zona Norte-Norte de Costa Rica.

Los mapas elaborados de uso/cobertura de la tierra de la Zona NorteNorte a escala 1:25000, se encuentran disponibles en su formato digital en la página de la Mapoteca Virtual de la Escuela de Ciencias Geográficas de la Universidad Nacional de Costa Rica.

http://www.mapoteca.geo.una.ac.cr/index.php/introcarto/193-zonanorte-norte-de-costa-rica.html 
Omar Barrantes Sotela, Luis Sandoval Murillo. Uso/cobertura de la tierra en los cantones de Upala, Guatuso y Los Chiles en el año 2011

DOI: http://dx.doi.org/10.15359/rgac.1-56.3

\section{Referencias}

Acuña, G. (2006). Piña en Costa Rica: producción y ambiente. Ambientico, p. 4. Heredia.

Ag, R. (2010). RapidEye Standard Image Product Specifications, (May), $1-54$.

Ahmadi, A., Karamouz, M., Moridi, A., \& Han, D. (2012). Integrated Planning of Land Use and Water Allocation on a Watershed Scale Considering Social and Water Quality Issues. Journal of Water Resources Planning \& Management, 138(6), 671-681. Retrieved from http://search.ebscohost.com.una.idm.oclc.org/login.aspx?direct=tru $\mathrm{e} \& \mathrm{db}=\mathrm{a} 9 \mathrm{~h} \& \mathrm{AN}=83183625 \&$ lang $=$ es\&site $=$ ehost-live

Alarcón, J. (2006). Factores, predicción e implicaciones en la asignación de usos del suelo: Revisión y reflexiones. Cuadernos de Investigación Geográfica, (32), 147-160. Retrieved from http://dialnet.unirioja.es/descarga/articulo/2283774.pdf

Anderson, J. R., Hardy, E. E., Roach, J. T., Witmer, R. E., \& Peck, D. L. (1976). A Land Use And Land Cover Classification System For Use With Remote Sensor Data. A Revision of the Land Use Classification System as Presented in U.S. Geological Survey Circular 671, 964, 41. Arroyo, M. (2009). Cobertura de la tierra en la Cuenca del Río Frío y el Humedal Medio Queso, Alajuela, Costa Rica. San José.

Bahadur, K. K. C. (2009). Improving Landsat and IRS Image Classification: Evaluation of Unsupervised and Supervised Classification through Band Ratios and DEM in a Mountainous Landscape in Nepal. Remote Sensing, 1(4), 1257-1272. Retrieved from http://search. ebscohost.com.una.idm.oclc.org/login.aspx?direct $=$ true $\& \mathrm{db}=\mathrm{a} 9 \mathrm{~h} \&$ AN $=47732082$ \&lang $=$ es\&site $=$ ehost-live

Baraldi, A., Bruzzone, L., \& Blonda, P. (2005). Quality Assessment of Classification and Cluster Maps Without Ground Truth Knowledge. IEEE Transactions on Geoscience \& Remote Sensing, 43(4), 857873. Retrieved from http://search.ebscohost.com.una.idm.oclc.org/ login.aspx?direct=true $\& \mathrm{db}=\mathrm{a} 9 \mathrm{~h} \& \mathrm{AN}=16642561 \&$ lang $=\mathrm{es} \&$ site $=\mathrm{e}$ host-live

Barrantes, O. (2012). Estructura del paisaje y su relación con el modelo de desarrollo territorial de la actividad turística en Tamarindo, Guanacaste 1971-2011. Universidad Nacional de Costa Rica. 
Barrantes, O. E., \& Sandoval, L. F. (2013). Zona Norte-Norte de Costa Rica: Hojas cartográficas de uso-cobertura de la tierra, 2011.

Chuvieco, E. (1999). Fundamentos de Teledetección Espacial (Segunda.). Madrid: Rialp.

Cohen, J. (1960). A Coefficient of Agreement for Nominal Scales. Educational and Psychological Measurement, 20(1), 37-46. doi:10.1177/001316446002000104

ECG-UNA. (2012a). Plan Regulador Guatuso: Etapa de Diagnóstico. Heredia.

ECG-UNA. (2012b). Plan Regulador Los Chiles: Etapa de Diagnóstico. Heredia.

ECG-UNA. (2012c). Plan Regulador Upala: Etapa de Diagnóstico. Heredia.

Ellis, E. C., Neerchal, N., Peng, K., Xiao, H. S., Wang, H., Zhuang, Y., ... Yang, L. Z. (2009). Estimating Long-Term Changes in China's Village Landscapes, 279-297. doi:10.1007/s10021-008-9222-4

Foody, G. M. (2008). Harshness in image classification accuracy assessment. International Journal of Remote Sensing, 29(11), 31373158. doi:10.1080/01431160701442120

Foody, G. M. (2009). Sample size determination for image classification accuracy assessment and comparison. International Journal of Remote Sensing, 30(20), 5273-5291. doi:10.1080/01431160903130937

Foody, G. M. G. M., Strahler, A. H., Boschetti, L., Friedl, M. a., Hansen, M. C., Herold, M., ... Woodcock, C. E. (2005). Local characterization of thematic classification accuracy through spatially constrained confusion matrices. Change, 48pp(25), 51. doi:10.1080/01431 160512331326521

Huising, J. (1993). Land Use Zones and Land Use Patterns in the Atlantic Zone of Costa Rica. Wageningen: Ponsen and Looijen.

Huth, J., Kuenzer, C., Wehrmann, T., Gebhardt, S., Tuan, V. Q., \& Dech, S. (2012). Land Cover and Land Use Classification with TWOPAC: towards Automated Processing for Pixel- and Object-Based Image Classification. Remote Sensing, 4(9), 2530-2553. Retrieved from http://search.ebscohost.com.una.idm.oclc.org/login.aspx?direct=tru $\mathrm{e} \& \mathrm{db}=\mathrm{a} 9 \mathrm{~h} \& \mathrm{AN}=80913886 \&$ lang=es\&site=ehost-live 
Omar Barrantes Sotela, Luis Sandoval Murillo. Uso/cobertura de la tierra en los cantones de Upala, Guatuso y Los Chiles en el año 2011

DOI: http://dx.doi.org/10.15359/rgac.1-56.3

IICA, MAG-PDR, UCR. (2007). Dinámicas territoriales en la Zona Norte de Costa Rica. IICA.

Jung, H.-W. (2003). Evaluating interrater agreement in SPICE-based assessments. Computer Standards \& Interfaces, 25(5), 477.

Krystyna, J., \& Da, N. (2009). RapidEye - Initial findings of Geometric Image Quality Analysis. doi:10.2788/52504

Laba, M., Gregory, S. K., Braden, J., Ogurcak, D., Hill, E., Fegraus, E., ... DeGloria, S. D. (2002). Conventional and fuzzy accuracy assessment of the New York Gap Analysis Project land cover map. Remote Sensing of Environment, 81(2/3), 443. Retrieved from http:// search.ebscohost.com.una.idm.oclc.org/login.aspx?direct=true \&db $=\mathrm{a} 9 \mathrm{~h} \& \mathrm{AN}=7797659 \&$ lang $=$ es \& $\mathrm{site}=$ ehost-live

Landis, J. R., \& Koch, G. G. (1977). The Measurement of Observer Agreement for Categorical Data. Biometrics, 33(1), pp. 159-174. Retrieved from http://www.jstor.org/stable/2529310

Leo, P., Eijsackers, H. J. P., Koelmans, A. A., \& Vijver, M. G. (2008). Ecological effects of diffuse mixed pollution are site-specific and require higher-tier risk assessment to improve site management decisions: A discussion paper. Science of the Total Environment, 406(3), 503-517. Retrieved from http://search.ebscohost.com.una.idm.oclc. org/login.aspx?direct $=$ true $\& d b=a 9 h \& A N=34743286 \&$ lang=es\&sit $\mathrm{e}=$ ehost-live

Lillesand, T., Kieffer, R. W., \& Chipman, J. (2007). Remote sensing and image interpretation (6th ed.). New York: John Wiley and Sons.

Marçal, A. R. S., Borges, J. S., Gomes, J. A., \& Da Costa, J. F. P. (2005). Land cover update by supervised classification of segmented ASTER images. International Journal of Remote Sensing, 26(7), 13471362. Retrieved from http://search.ebscohost.com/login.aspx?direct $=$ true $\& \mathrm{db}=\mathrm{a} 9 \mathrm{~h} \& \mathrm{AN}=17000023 \&$ lang $=$ es $\&$ site $=$ ehost-live

Mather, A. S. (1986). Land use. New York: Longman.

Meyer, W. B., \& Turner, B. L. (1994). Changes in Land Use and Land Cover: A Global Perspective. Cambridge University Press.

Muchoney, D., Borak, J., Chi, H., Friedl, M., Gopal, S., Hodges, J., ... Strahler, A. (2000). Application of the MODIS global supervised classification model to vegetation and land cover mapping of Central America. International Journal of Remote Sensing, 21(6), 
1115-1138. Retrieved from http://search.ebscohost.com.una.idm. oclc.org/login.aspx ?direct $=$ true $\& d b=a 9 h \& A N=3818336 \&$ lang $=$ es \&site $=$ ehost-live

Naiman, R. J., Fetherston, K. L., Mckay, S. J., \& Chen, J. (1998). Riparian Forests. River Ecology and Management: Lessons from the Pacific Coastal Ecoregion, 289-323. doi:10.1016/S0378-1127(00)00623-X Naughton, D., Brunn, A., Czapla-Myers, J., Douglass, S., Thiele, M., Weichelt, H., \& Oxfort, M. (2011). Absolute radiometric calibration of the RapidEye multispectral imager using the reflectance-based vicarious calibration method. Journal of Applied Remote Sensing, 5(1), 053544. doi:10.1117/1.3613950

No-Wook, P. (2010). Accounting for temporal contextual information in land-cover classification with multi-sensor SAR data. International Journal of Remote Sensing, 31(2), 281-298. Retrieved from http:// search.ebscohost.com.una.idm.oclc.org/login.aspx?direct $=$ true $\& d b$ $=\mathrm{a} 9 \mathrm{~h} \& \mathrm{AN}=49143172 \&$ lang $=$ es\&site $=$ ehost-live

Olofsson, P., Foody, G. M., Herold, M., Stehman, S. V, Woodcock, C. E., \& Wulder, M. A. (2014). Remote Sensing of Environment Good practices for estimating area and assessing accuracy of land change. Remote Sensing of Environment, 148, 42-57. doi:10.1016/j. rse.2014.02.015

PNUD. (2013). Informe nacional sobre desarrollo humano 2013. (P. de las Naciones Unidas para el Desarrollo, Ed.) (1st ed.). San José: PNUDCosta Rica.

Pontius, R. G., \& Millones, M. (2011). Death to Kappa: birth of quantity disagreement and allocation disagreement for accuracy assessment. International Journal of Remote Sensing, 32(15), 4407-4429. doi:1 $0.1080 / 01431161.2011 .552923$

Ramírez, I. (2001). Cambios en las cubiertas del suelo en la Sierra de Angangueo,MichoacányEstadodeMéxico,1971-1994-2000.Investigaciones Geográficas, 39-55. Retrieved from http://www.scielo.org.mx/scielo. php?script=sci_arttext\&pid=S0188-46112001000200004\&nrm=iso

Riaño, D., Salas, J., \& Chuvieco, E. (2000). Corrección Atmosférica y Topográfica , Información Multitemporal y Auxiliar Aplicadas a la Cartografía de Modelos de Combustibles con Imágenes LandsatTM. Tecnologías Geográficas Para El Desarrollo Sostenible: IX 
Omar Barrantes Sotela, Luis Sandoval Murillo. Uso/cobertura de la tierra en los cantones de Upala, Guatuso y Los Chiles en el año 2011

DOI: http://dx.doi.org/10.15359/rgac.1-56.3

Congreso Del Grupo de Métodos Cuantitativos, Sistemas de Información Geográfica Y Teledetección, 222-239.

Richters, E. J. (1995). Manejo del uso de la tierra en América Central: hacia el aprovechamiento sostenible del recurso tierra. Instituto Interamericano de Cooperación para la Agricultura. Retrieved from $\mathrm{http} / / /$ books.google.co.cr/books?id=jP8zb7ClCMUC

Rojas Rodríguez, F., Arias Aguilar, D., Moya Roque, R., Meza Montoya, A., Murillo Gamboa, O., \& Marcela Gamboa, A. (2004). MANUAL PARA PRODUCTORES DE MELINA Gmelina arborea EN COSTA RICA, 234.

Rosenfield, G. H. (1986). A coefficient of agreement as a measure of thematic classification accuracy. Photogrammetric Engineering and Remote Sensing (PE\&RS), 52(2), 223-227.

Ruelland, D., Dezetter, A., Puech, C., \& Ardoin-Bardin, S. (2008). Long-term monitoring of land cover changes based on Landsat imagery to improve hydrological modelling in West Africa. International Journal of Remote Sensing, 29(12), 3533-3551. doi:10.1080/01431160701758699

Sage, R. V., De Camino, M., \& Alfaro, L. F. M. (2002). TEAK (Tectona grandis) IN CENTRAL AMERICA.

Sampath, A., \& Chander, G. (2010). Radiometric \& Geometric Assessment of the Data from RapidEye Constellation of Satellites JACIE Meeting March 16-18, 2010.

Sampath, A., Haque, O., Chander, G., \& Edge, R. (2011). Radiometric $\&$ Geometric Assessment of Data from RapidEye Constellation of Satellites, (5 m), 2011.

Smith, M. D., \& Giraud, D. (2006). Traditional Land-Use Planning Regulation and Agricultural Land Conservation: A Case Study from the USA. Planning Practice \& Research, 21(4), 407-421. Retrieved from http://search.ebscohost.com.una.idm.oclc.org/login.aspx?direc $\mathrm{t}=$ true $\& \mathrm{db}=\mathrm{a} 9 \mathrm{~h} \& \mathrm{AN}=27728403$ \&lang $=$ es\& site $=$ ehost-live

Strahler, A. H., Boschetti, L., Foody, G. M., Friedl, M. a., Hansen, M. C., Herold, M., ... Woodcock, C. E. (2006). Global Land Cover Validation: Recommendations for Evaluation and Accuracy Assessment of Global Land Cover Maps. Change, 48pp(25), 51. Retrieved from http://landval.gsfc.nasa.gov/pdf/GlobalLandCoverValidation.pdf 
Tang, J., Wang, L., \& Myint, S. W. (2007). Improving urban classification through fuzzy supervised classification and spectral mixture analysis. International Journal of Remote Sensing, 28(18), 4047-4063. Retrieved from http://search.ebscohost.com.una.idm.oclc.org/login.aspx ?direct $=$ true $\& d b=a 9 h \& A N=26419275 \&$ lang $=$ es\&site $=$ eho st-live

Tapsall, B., Milenov, P., \& Tas, K. (2010). ANALYSIS OF RAPIDEYE IMAGERY FOR ANNUAL LANDCOVER MAPPING AS AN AID TO EUROPEAN UNION ( EU ) COMMON AGRICULTURAL POLICY, XXXVIII, 568-573.

Ugalde, L. (1997). Teca (Tectona grandis): Resultados de investigación silvicultural del proyecto MADELEÑA en América Central. Turrialba.

Wilhelm-Rechmann, A., \& Cowling, R. M. (2013). Local land-use planning and the role of conservation: An example analysing opportunities. South African Journal of Science, 109(3/4), 42-47. Retrieved from http://search.ebscohost.com.una.idm.oclc.org/login.aspx?direc $\mathrm{t}=$ true \& $\mathrm{db}=\mathrm{a} 9 \mathrm{~h} \& \mathrm{AN}=89763181$ \&lang=es\&site=ehost-live

Wong, G., Sáenz, J., \& Carrillo, E. (1999). Mamíferos del Parque Nacional Corcovado, Costa Rica. Santo Domingo: INBio.

Wundram, D., \& Löffler, J. (2008). High-resolution spatial analysis of mountain landscapes using a low-altitude remote sensing approach. International Journal of Remote Sensing, 29(4), 961-974. doi:10.1080/01431160701352113

Zhang, N., \& Chen, Y. (2014). A case study of the upwind urbanization influence on the urban heat Island effects along the Suzhou-Wuxi corridor. Journal of Applied Meteorology and Climatology, 53, 333345. doi:10.1175/JAMC-D-12-0219.1 